\title{
Síndrome de Patau por translocación recíproca entre los cromosomas 10 y 13
}

\author{
Patau syndrome by reciprocal translocation between chromosomes 10 and 13 \\ María José Peláez-Cantero, ${ }^{*,+}$ Inmaculada Delicado-Calderón,* Laura Sánchez-Torres* \\ * Hospital Regional Universitario de Málaga. Materno Infantil. Málaga, España.
}

\begin{abstract}
RESUMEN
Se trata del caso de un recién nacido masculino con diagnóstico de síndrome de Patau, en quien se determinó que la causa fue translocación recíproca entre los cromosomas 10 y 13 , lo cual es una variante poco común. Se presentan las imágenes del caso, así como los hallazgos de cariotipo.
\end{abstract}

Palabras clave: Síndrome de Patau, trisomía 13, traslocación 10, 13.

\section{INTRODUCCIÓN}

El síndrome de Patau es una entidad poco frecuente que afecta a $1 / 20,000$ recién nacidos $(\mathrm{RN})$ vivos. ${ }^{1}$ En la mayoría de los casos ocurre por trisomía del cromosoma 13 , aunque en $20 \%$ se debe a translocación y hasta en un $6 \%$ a mosaicismo. Las principales manifestaciones clínicas incluyen holoprosencefalia, retraso del desarrollo psicomotor, anomalías cardiacas y renales. ${ }^{2}$ Para su diagnóstico se requiere realizar cariotipo para identificar la trisomía o translocación; en casos de mosaicismo se debe demostrar la presencia de células con 46 y 47 cromosomas mediante el análisis de fibroblastos o en linfocitos. ${ }^{3}$ La mortalidad es $>90 \%$ en el primer año de vida, principalmente por la morbilidad cardiovascular. ${ }^{4}$

\footnotetext{
+Correspondencia: MJPC, pelaez_mariajose@hotmail.com Conflicto de intereses: Los autores declaran que no tienen. Citar como: Peláez-Cantero MJ, Delicado-Calderón I, SánchezTorres L. Síndrome de Patau por translocación recíproca entre los cromosomas 10 y 13. Rev Mex Pediatr. 2020; 87(6); 244-246. https://dx.doi.org/10.35366/97689
}

\begin{abstract}
This is the case of a male newborn with a diagnosis of Patau syndrome; genetic cause was an uncommon variant, a reciprocal translocation between chromosomes 10 and 13 . Clinical images of the patient as well as karyotype findings are presented.
\end{abstract}

Keywords: Patau syndrome, trisomy 13 syndrome, translocation 10, 13.

\section{CASO CLÍNICO}

Presentamos el caso de un varón $\mathrm{RN}$, pretérmino de 34 semanas de gestación. Fue el primogénito de padres jóvenes sanos, no consanguíneos. La madre había presentado cuatro abortos espontáneos previos. El embarazo cursó sin complicaciones; sin embargo, requirió cesárea urgente porque se detectó por ultrasonido retraso en el crecimiento intrauterino tipo II. Al nacimiento presentó distrés respiratorio que requirió soporte con ventilación. A la exploración física destacaba facies dismórfica (Figura 1), hipertelorismo, raíz nasal ancha, pabellones auriculares de implantación límite, labio superior fino, anquiloglosia, cuello corto con pliegue nucal redundante, hipotonía axial, criptorquidia bilateral y polidactilia en ambos pies (Figura 2). En fondo de ojo, papilas con gran excavación y zona central con coloboma en ojo derecho.

En ecografía craneal había signos de vasculopatía mineralizante bilateral; en ecocardiograma se detectó conducto arterioso permeable e hipertensión pulmonar grave. A nivel abdominal, por ecografía se detectó que los riñones tenían mala diferenciación corticomedular 
y microquistes bilaterales, ectasia piélica derecha leve, testículo derecho intraabdominal, sin visualizar el izquierdo. Posteriormente, se confirmó reflujo vesicoureteral izquierdo grado II-III.

Durante su estancia presentó ictericia y un episodio de crisis convulsivas en hemicuerpo izquierdo de escasa duración; en el EEG se objetivó lentificación de la actividad de base, focalizado a región temporo-frontal bilateral ocasional, por lo que se inició tratamiento con fenobarbital.

Ante los hallazgos clínicos, se realizó cariotipo en sangre periférica mediante técnica de bandas GTG. Tras el estudio de 20 metafases, con una resolución cromosómica de 500 bandas, se obtuvo la fórmula cromosómica 46,XY,der(10)t(10;13)(q26.3;q13). En el estudio citogenético se detectó la presencia de un cro-

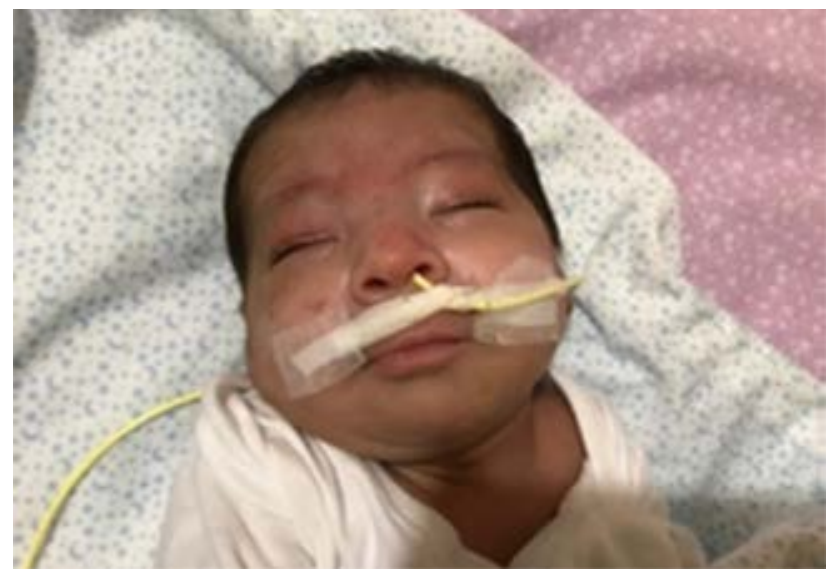

Figura 1: Facies dismórfica, hipertelorismo, raíz nasal ancha, labio superior fino, cuello corto, orejas de implantación límite. Porta sonda nasogástrica, necesaria para la nutrición.

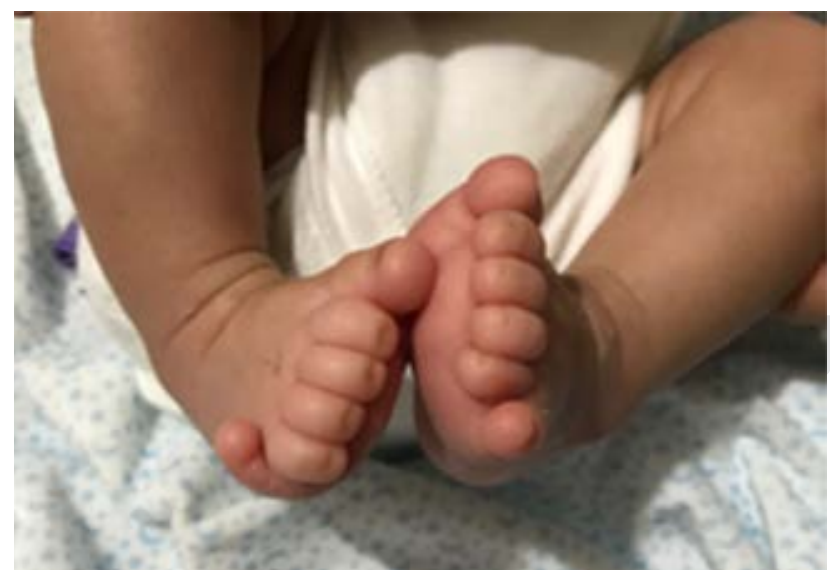

Figura 2: Polidactilia en ambos pies.

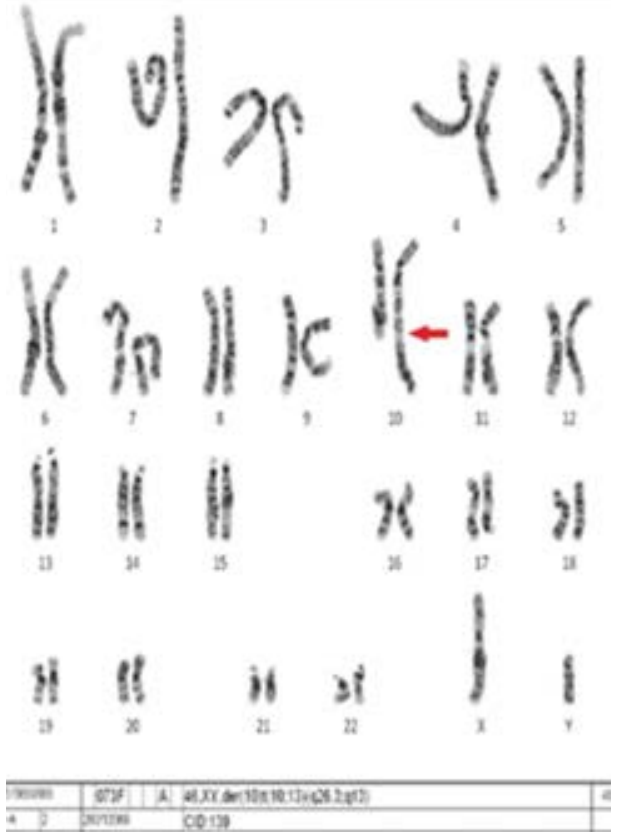

Figura 3: Se aprecian 46 cromosomas, y en el cromosoma 10 podemos observar cómo hay adherido un fragmento adicional de material genético, procedente del cromosoma 13.

mosoma 10 derivativo, originado por una translocación recíproca entre los cromosomas 10 y 13 (Figura 3), producida por una reorganización desequilibrada, lo que produce una trisomía casi completa del cromosoma 13 y una monosomía 10q terminal.

Se realizó cariotipo a los progenitores para determinar si la alteración era heredada o mutación de novo. En el cariotipo paterno se obtuvo una fórmula cromosómica normal, en cambio, en el materno se detectó la misma translocación balanceada a la del neonato, indicando que la alteración detectada en el paciente se debe a la presencia de la translocación materna. Lo anterior podría explicar los abortos espontáneos de repetición.

Hubo asesoramiento genético ante la posibilidad de nuevo embarazo, recomendándose diagnóstico genético preimplantacional o diagnóstico prenatal. En la actualidad, nuestro paciente tiene 20 meses y presenta retraso psicomotor grave, epilepsia sintomática, así como atrofia óptica con papilas pseudocolobomatosas y cataratas parciales bilaterales.

\section{DISCUSIÓN}

La detección de este tipo de variantes de un síndrome considerado letal hace replantearnos la manera en 
que se debe actuar ante situaciones de riesgo vital, ya que siempre se ha determinado la adecuación del esfuerzo terapéutico en estos pacientes. ${ }^{5-7}$ Supone para el médico un dilema ético importante, ya que las recomendaciones a los padres incluyen desde interrumpir el embarazo hasta continuarlo, o dar opciones para prolongar la vida. ${ }^{8}$

La variante detectada en nuestro caso no está descrita en la literatura, por lo que más allá del consejo genético a los padres no podemos aventurar el pronóstico del niño. Hay pocos casos publicados en la literatura y, dentro de éstos, hay heterogeneidad en las alteraciones que presentan en el cromosoma 13, con evolución variable. Como datos comunes, predomina un retraso psicomotor grave y un pronóstico diferente al síndrome de Patau clásico. ${ }^{9-12}$

\section{REFERENCIAS}

1. BS Giersch. Congenital cytogenetic abnormalities. UpToDate [September 2019]. Available in: https://ws003.sspa. juntadeandalucia.es:2060/contents/congenital-cytogeneticabnormalities?search=partial\%20trisomy\%2013\&source=search result\&selectedTitle $=1 \sim 150 \&$ usage_type $=$ default\&display_ rank $=1 \# \mathrm{H} 14$

2. Springett A, Wellesley D, Greenlees R, Loane M, Addor MC, Arriola $L$ et al. Congenital anomalies associated with trisomy 18 or trisomy 13: A registry-based study in 16 European countries, 2000-2011. Am J Med Genet A. 2015; 167A(12): 3062-3069.
3. Alberman E, Mutton D, Morris JK. Cytological and epidemiological findings in trisomies 13,18, and 21: England and Wales 20042009. Am J Med Genet A. 2012; 158A(5): 1145-1150.

4. Wu J, Springett A, Morris JK. Survival of trisomy 18 (Edwards syndrome) and trisomy 13 (Patau Syndrome) in England and Wales: 2004-2011. Am J Med Genet A. 2013; 161A(10): 2512-2518.

5. Lakovschek IC, Streubel B, Ulm B. Natural outcome of trisomy 13 , trisomy 18 , and triploidy after prenatal diagnosis. Am J Med Genet A. 2011; 155A(11): 2626-2633.

6. Baty BJ, Blackburn BL, Carey JC. Natural history of trisomy 18 and trisomy 13: I. Growth, physical assessment, medical histories, survival, and recurrence risk. Am J Med Genet. 1994; 49(2): 175-188.

7. Carey JC. Emerging evidence that medical and surgical interventions improve the survival and outcome in the trisomy 13 and 18 syndromes. Am J Med Genet A. 2020; 182(1): 13-14.

8. Pyle AK, Fleischman AR, Hardart G, Mercurio MR. Management options and parental voice in the treatment of trisomy 13 and 18 . $J$ Perinatol. 2018; 38(9): 1135-1143.

9. Kaye Cl, Booth CW, Meeker D, Nadler HL. Cleft palate and multiple anomalies in one of two siblings with partial 13 trisomy. Cleft Palate J. 1977; 14(3): 244-248.

10. Douglas C, Smith SA, Rohena L. Novel case of paternal paracentric inversion causing partial trisomy 13 and review of the literature. Am J Med GenetA. 2017; 173(6): 1673-1680. doi: 10.1002/ajmg.a.38192

11. González-del Angel A, Estandia-Ortega B, Gaviño-Vergara A, Sáez-de-Ocariz M, Velasco-Hernández Mde L, Salas-Labadía C. A patient with trisomy 13 mosaicism with an unusual skin pigmentary pattern and prolonged survival. Pediatr Dermatol. 2014; 31(5): 580-583. doi: 10.1111/pde.12339.

12. Haug S, Goldstein M, Cummins D, Fayard E, Merritt TA. Using patient-centered care after a prenatal diagnosis of trisomy 18 or trisomy 13: a review. JAMA Pediatr. 2017; 171(4): 382-387. 